\title{
Integration of Replication-defective R68.45-like Plasmids into the Pseudomonas aeruginosa Chromosome
}

\author{
By CORNELIA REIMMANN, MANUELA RELLA $\dagger$ AND DIETER HAAS* \\ Mikrobiologisches Institut, Eidgenössische Technische Hochschule, CH-8092 Zürich, Switzerland
}

(Received 14 January 1988; revised 12 February 1988)

\begin{abstract}
R68.45 and other similar broad-host-range (IncP) plasmids carrying a tandem repeat of the $2 \cdot 1 \mathrm{~kb}$ insertion element IS 21 mobilize the chromosome of many different Gram-negative bacteria. To analyse the structure of R68.45-chromosome cointegrates, whose involvement in the mobilization process had been postulated previously, we selected for the stable integration of R68.45-like plasmids into the Pseudomonas aeruginosa chromosome. Two plasmids were chosen : pME28, a transfer-deficient, mobilizable RP1 derivative with an inactive replication control $(\operatorname{trf} A)$ gene, and pME487, an R68.45 derivative with a $\operatorname{trf} A(\mathrm{ts})$ mutation causing temperaturesensitive replication. Chromosomally integrated pME28 and pME487 were found to be flanked by single IS21 elements. This structure is in agreement with a 'cut-and-paste' mode of R68.45 transposition. pME28 and pME487 showed a low specificity of insertion but rarely $(<0.1 \%)$ induced auxotrophic mutations. $\mathrm{Hfr}$ (high-frequency-of-recombination) donors of $P$. aeruginosa could be obtained by chromosomal integration of pME487 or pME28; in the latter case, the transfer functions lacking from pME28 had to be provided in trans on an autonomous plasmid. Hfr donors gave higher conjugational linkage and transferred longer stretches of the $P$. aeruginosa chromosome than did R68.45 donors. This suggests that the integration of R68.45 into the donor chromosome is short-lived in P. aeruginosa.
\end{abstract}

\section{INTRODUCTION}

The broad-host-range IncP plasmid R68.45 mobilizes the chromosome of a large number of Gram-negative bacterial species (Holloway, 1979; Haas \& Reimmann, 1988). The 2.1 kb

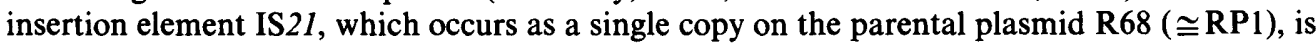
tandemly repeated on R68.45 (Riess et al., 1980; Willetts et al., 1981). The IS21 tandem repeat is essential for the chromosome-mobilizing ability (Cma) of R68.45 (Currier \& Morgan, 1982; Haas \& Riess, 1983). In Pseudomonas aeruginosa, R68.45 mobilizes the chromosome from many origins and in both orientations (Haas \& Holloway, 1978). It has been postulated that Cma results from the random integration of $\mathrm{R} 68.45$ into the chromosome via IS21-dependent transposition (Willetts et al., 1981). However, stable chromosomal integration of R68.45 has not been observed; that is, spontaneous $\mathrm{Hfr}$ (high-frequency-of-recombination) strains have not been isolated from R68.45 donors in different bacterial species (Haas \& Reimmann, 1988). Hence the structure of the postulated R68.45-chromosome cointegrate is unknown. It appears that replication-proficient IncP plasmids are not maintained stably in the chromosome of Escherichia coli or P. aeruginosa without specific selective pressure (Martin et al., 1981; Grinter, 1984; Reimmann \& Haas, 1986).

When R68.45 mobilizes nonconjugative plasmids in E. coli, cointegrates are formed which are stable in recA strains. Single IS21 copies in the same orientation are found at the junctions between R68.45 and the mobilized plasmid (Riess et al., 1983). Current evidence suggests that

Abbreviations: Cma, chromosome-mobilizing ability; ts, temperature-sensitive.

† Present address: CIBA-GEIGY AG, R-1040B.P.46, CH-4002 Basel, Switzerland. 
E. coli

S17-1

ED8654

$P$. aeruginosa

PAO236

PAO6049

PAO6231

PA06236

PAO6049ura: :pME28

PAO6049 : : pME28-5,

PA06049:: pME28-9,

PA06049: : pME28-17

PTO6017

PTO6025

PTO6034

$\left.\begin{array}{c}\text { PTO6038, } \\ \text { PTO6039, } \\ \text { PTO6040 }\end{array}\right\}$

Plasmids

R68.45

pACYC184: : IS21-91

pME28

pME206

pME301

pME472

pME487

pUB307
Table 1. Bacterial strains and plasmids

Genotype/phenotype*

pro thi hsdR $h s d M^{+}$recA; chromosomally integrated RP4-2 (Tn $1::$ ISR 1 , Tc : : Mu Km: :Tn7)

metB hsdR hsd $M^{+} \operatorname{supE}$ supF

ilv-226 hisII4 lysA12 met-28 trp-6 proA82 nalA2 met-9011 amiE200 strA

ilv-226 hisII4 lysA12 ser-3 trp-6 proA82

met-9011 amiE200 strA trpE: :pME28†

met-9011 amiE200 strA ura: :pME28

met-9011 amiE200 strA; chromosomally integrated pME28

leu-10 rec-102 str $A$; chromosomally integrated pME14 (=pME134::IS21)

leu-10 rec-102 str $A$

leu-10 rec-102 str $A$; chromosomally integrated pME487

leu-10 rec-102 strA; chromosomally integrated pME487

Ap/Cb Tc Km Tra Cma IncP-1; (IS21)

Tc Cm P15A replicon

Tc Km $\Delta$ (Tra2-Tra3-TrfA) IncP-1; (IS 21$)_{2}$

Ap/Cb Km Tra IncP-1

Ap/Cb Tc Km Tra Rep(ts) IncP-1

Tc Km Tra Cma IncP-1; (IS21),

Tc Km Tra Cma Rep(ts) IncP-1; (IS 21)

Tc Km Tra IncP-1
Reference or construction

Simon et al. (1983)

Borck et al. (1976)

Haas \& Holloway (1976)

Rella et al. (1985)

This work $\dagger$

This work

This work

This work

Reimmann \& Haas (1986)

Reimmann \& Haas (1986)

This work (Fig. 4)

This work

Haas \& Holloway (1976)

Riess et al. (1983)

Reimmann \& Haas (1987);

Fig. $1(b)$

Rella et al. (1987)

Watson (1980)

This work (Methods)

This work (Fig. 1a)

Bennett et al. (1977)

*Symbols are according to Holloway \& Morgan (1986) and Novick et al. (1976). Tandem repeats of IS21 are denoted by (IS 21$)_{2}$.

†met-28 of PAO222 (Haas \& Holloway, 1976) was replaced by ser-3 of PAO2 (Isaac \& Holloway, 1968).

¥Growth of PAO6236 with an anthranilate supplement indicates mutation in trpE.

IS 21 transposase preferentially cuts R68.45 between the tandemly repeated IS 21 copies and then the entire R68.45 plasmid is inserted into the target replicon (Reimmann \& Haas, 1987). This model leads to two predictions concerning the integration of R68.45-like plasmids into the bacterial chromosome. (i) The integrated plasmid should be flanked by single IS 21 copies. (ii) Integration should produce chromosomal mutations. As we show here, both predictions hold true when replication-defective IncP plasmids carrying an IS21 tandem repeat are integrated into the $P$. aeruginosa chromosome. From linkage date we infer that cointegrates between the replication-proficient R68.45 and the $P$. aeruginosa chromosome are unstable.

\section{METHODS}

Strains and plasmids. These are listed in Table 1.

Media, growth conditions, and genetic techniques. They have all been described before (Stanisich \& Holloway, 1972; Haas \& Holloway, 1976; Reimmann \& Haas, 1986, 1987).

Carbenicillin enrichment for tetracycline-sensitive cells. Overnight cultures of $P$. aeruginosa PAO6049::pME28 were diluted into fresh nutrient broth and grown with shaking to $10^{8}$ cells $\mathrm{ml}^{-1}$. Tetracycline was added to a final concentration of $20 \mu \mathrm{g} \mathrm{ml}^{-1}$. After $1 \mathrm{~h}$ incubation, carbenicillin (final concentration $2 \mathrm{mg} \mathrm{ml}^{-1}$ ) was added and incubation was continued overnight. Cells were washed and the enrichment cycle was repeated once. After plating on nutrient agar, tetracycline-sensitive derivatives, which had lost the integrated pME28, were identified by replica plating. 

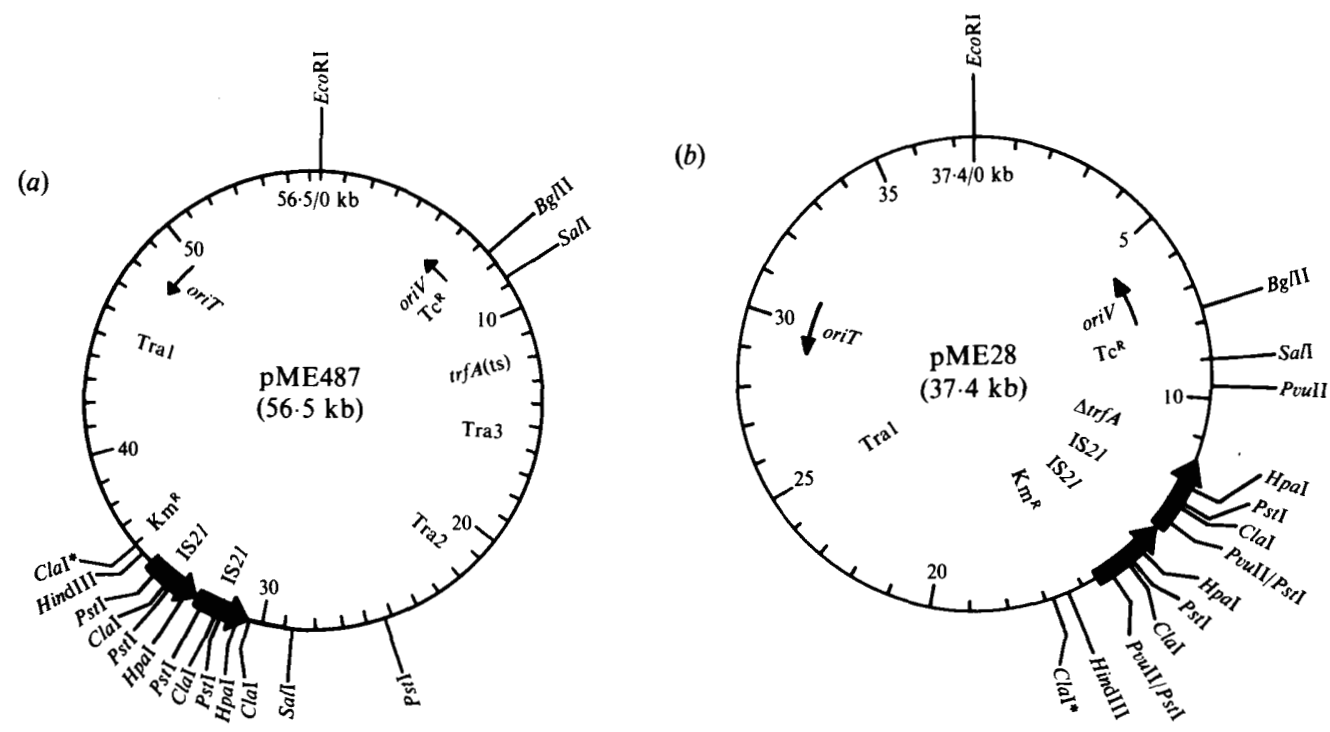

Fig. 1. Restriction maps of IncP plasmids with an IS21 tandem repeat. Heavy arrows denote IS21. Tc ${ }^{\mathrm{R}}$, tetracycline resistance; $\mathrm{Km}^{\mathrm{R}}$, kanamycin resistance; Tra1, Tra2, Tra3, transfer gene regions; oriV, origin of vegetative replication; oriT, origin of transfer; $\operatorname{trfA}$, replication control locus; ClaI*, restriction site protected by methylation in $d_{a m^{+}} E$. coli but not in $P$. aeruginosa (Haas \& Riess, 1983). pME487 $(a)$ is an R68.45 derivative constructed as described in Methods. pME28 $(b)$ is an RP1 derivative (Reimmann \& Haas, 1987). Note that R68 and RP1 are very similar plasmids (Willetts et al., 1981). The IS21 elements of pME28 are functionally indistinguishable from those of R68.45 (Reimmann \& Haas, 1987).

DNA manipulations. Conditions for plasmid isolation, restriction, ligation and Southern transfer have been given elsewhere (Itoh et al., 1984; Reimmann \& Haas, 1986).

Construction of $p M E 487$. The $49 \mathrm{~kb} E c 0$ RI-BglII fragment of R68.45 (Haas \& Riess, 1983) and the $7.5 \mathrm{~kb}$ EcoRI-BgIII fragment of pUB307 (=RPI $\Delta \mathrm{Tn} 1$; Bennett et al., 1977) were ligated to produce pME472

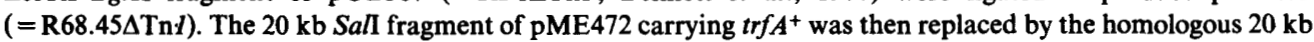
SalI fragment of pME301 [= RP1Rep(ts)], which carries a $\operatorname{trf} A(\mathrm{ts})$ mutation (Rella et al., 1987). The resulting recombinant, pME487 (Fig. 1 a), was temperature sensitive for replication at $43^{\circ} \mathrm{C}$ in $E$. coli and in $P$. aeruginosa and self-transmissible, although transfer frequencies appeared to be lower than those of RP1. Restriction analysis of pME487 showed that a spontaneous deletion of about $0.1 \mathrm{~kb}$ had occurred in the $1.3 \mathrm{~kb} \mathrm{Bg} / \mathrm{II}-\mathrm{SalI}$ fragment near oriV, but this had no apparent effect on the plasmid phenotype.

\section{RESULTS}

\section{Chromosomal integration of pME487}

We first chose pME487, a temperature-sensitive derivative of R68.45 without the TEM-2 $\beta$-lactamase transposon Tnl (Fig. la), to study the interaction of R68.45-like plasmids with the $P$. aeruginosa chromosome. The temperature sensitivity of pME487 is due to mutation in the trans-acting replication control gene $\operatorname{trf} A$. In $E$. coli pME487 formed cointegrates with pBR325 at frequencies of $10^{-3}-10^{-4}$. These frequencies were calculated as the ratio of cointegrate transfer per pME487 transfer (i.e. transfer of chloramphenicol resistance per transfer of kanamycin resistance) in a mating-out assay with a streptomycin-resistant $E$. coli recipient (Reimmann \& Haas, 1987). pME487 and pBR325 were joined together by single IS21 copies (data not shown), as expected from previous work on R68.45 (Riess et al., 1983). pME487 was transferred from $E$. coli ED8654 to the recombination-deficient $P$. aeruginosa mutant PTO6025 at permissive temperature $\left(30^{\circ} \mathrm{C}\right)$; selection was made on nutrient agar containing streptomycin $\left(3000 \mu \mathrm{g} \mathrm{ml}^{-1}\right)+$ kanamycin $\left(200 \mu \mathrm{g} \mathrm{ml}^{-1}\right)+$ tetracycline $\left(100 \mu \mathrm{g} \mathrm{ml}^{-1}\right)$. Overnight cultures of $P$. aeruginosa transconjugants were then plated onto the same medium at non-permissive 


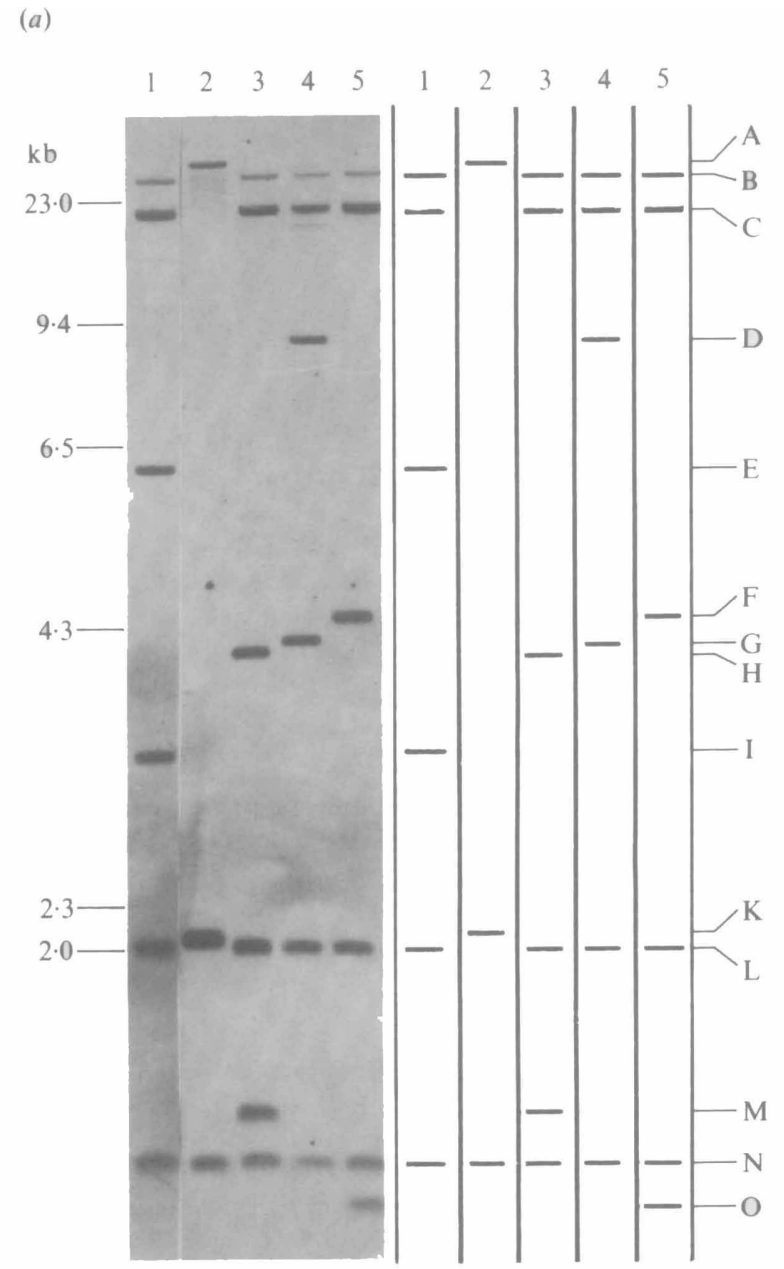

(b)

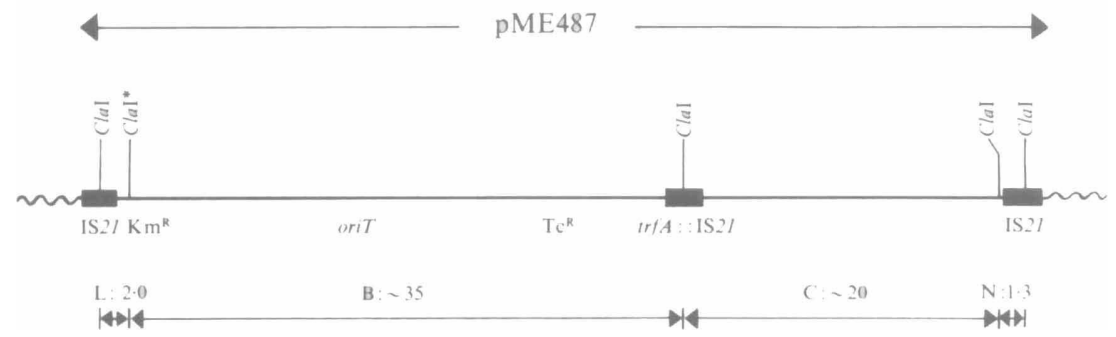

Fig. 2. Structure of chromosomally integrated pME487. (a) Southern hybridization of ClaI-digested chromosomal DNA with ${ }^{35}$ S-labelled pACYC184 : :IS $21-91$ as the probe. The chromosome is indicated by wavy lines. Abbreviations are the same as in Fig. 1. Lane 1, strain PTO6034; lane 2, pME487 control; lanes 3-5, strains PTO6038, PTO6039, and PTO6040, respectively. Bands D, E, F, G, H, I, M, $\mathrm{O}$ are chromosome-IS $2 I$ border fragments; band $\mathrm{K}$ is typical of an IS2I tandem repeat (found only in pME487); bands A, B, C, L, N are pME487-internal fragments; band A ( $\sim 5 \mathrm{~kb}$ ) occurred only in the pME487 control; band $\mathrm{L}(2.0 \mathrm{~kb})$ is missing from the pME487 control because of methylation of the Cla $\mathrm{I}^{*}$ site in $E$. coli. (b) Proposed structure of pME487 integrated into the $P$. aeruginosa chromosome. Letters refer to fragments in Fig. $2 a$. 
temperature $\left(43^{\circ} \mathrm{C}\right)$. Resistant colonies appeared at a frequency of about $10^{-6}$. They were purified several times until the kanamycin- and tetracycline-resistance markers were stably maintained at $30^{\circ} \mathrm{C}$ and $43^{\circ} \mathrm{C}$. Some strains, which carried pME487 integrated in the chromosome, were analysed further (PTO6034, PTO6038, PTO6039, PTO6040). No autonomous plasmid could be detected in cleared lysates of these strains. The strains were Hfr donors, transferring proximal markers at about $10^{-3}$ per donor. The origin of strain PTO6034 was mapped between proA and trp-6 (cf. Fig. 4). The other strains efficiently mobilized markers in the $0-20$ min region of the chromosome but their origins were not mapped.

The structure of the integrated pME487 was analysed by Southern hybridization of ClaI-cut chromosomal DNA extracted from the four Hfr strains, with a ${ }^{35}$ S-labelled IS 21 probe (Fig. $2 a$ ). The $2.1 \mathrm{~kb}$ band which is typical of the IS21 tandem repeat in pME487 (Fig. 2a, lane 2) was missing in all cases. If single IS21 copies flank the integrated plasmid, two pME487-internal bands of 2.0 and $1.3 \mathrm{~kb}$ plus two border fragments of varying length are expected and this pattern was found (Fig. $2 a$, lanes $1,3,4,5)$. In addition, two fragments of constant length ( $20 \mathrm{~kb}$ and $35 \mathrm{~kb}$; Fig. $2 a$, lanes $1,3,4,5)$ also hybridized to IS21. Since pME487 had no homology with the wild-type $P$. aeruginosa chromosome (data not shown), the $20 \mathrm{~kb}$ and $35 \mathrm{~kb}$ fragments indicate the presence of an additional IS 21 copy. Previous experiments have demonstrated that in many $P$. aeruginosa $\mathrm{Hfr}$ strains the $\operatorname{tr} f A$ gene of a chromosomally integrated, temperaturesensitive RP1 derivative is inactivated by an IS21 insertion (Reimmann \& Haas, 1986). This insertion may stabilize the plasmid-chromosome cointegrate by shutting off plasmid replication at any temperature. In keeping with this model, we propose that the $20 \mathrm{~kb}$ and $35 \mathrm{~kb}$ fragments originate from an IS21 insertion into the $\operatorname{trf} A$ region of the integrated pME487 (Fig. $2 b$ ). The proposed structure (Fig. $2 b$ ) is consistent with the ClaI digestions (Fig. 2a), but the precise location and the orientation of the internal IS21 copy have not been worked out.

\section{Chromosomal integration of pME28}

The foregoing experiments have demonstrated that a plasmid containing an IS 21 tandem repeat can insert into different chromosomal sites. This result was confirmed and extended by the use of pME28, a replication-deficient RP1 derivative (Reimmann \& Haas, 1987). pME28 carries tandemly repeated IS 21 elements adjacent to a partially deleted $\operatorname{trf} A$ gene (Fig. $1 b$ ). Hence, the plasmid depends on complementation by a functional $\operatorname{trf} A^{+}$gene for autonomous replication (Reimmann \& Haas, 1987). Because of a Tra2/Tra3 deletion, pME28 is not selftransmissible but mobilization can be effected when the transfer functions are supplied in trans. The $E$. coli strain S17-1, which carries a chromosomally integrated IncP plasmid (Simon et al., 1983), permits autonomous replication and mobilization of pME28 (Reimmann \& Haas, 1987). In a cross between strain S17-1(pME28) and $P$. aeruginosa PAO6049 as the recipient, $P$. aeruginosa(pME28) transconjugants were obtained at frequencies of $10^{-6}-10^{-7}$ per donor; selection was made on medium containing streptomycin $\left(3000 \mu \mathrm{g} \mathrm{ml}^{-1}\right)$, kanamycin $(200 \mu \mathrm{g}$ $\left.\mathrm{ml}^{-1}\right)$ and tetracycline $\left(100 \mu \mathrm{g} \mathrm{ml}^{-1}\right)$. In 10 transconjugants examined pME28 was found to be integrated into 10 different chromosomal sites, according to the variable sizes of pME28chromosome border fragments (Fig. $3 a$, lanes 1, 3, 5, 8, 10, showing the patterns of five representative strains). The integrated pME28 did not contain an IS 21 tandem, as judged by the absence of a $2.1 \mathrm{~kb}$ ClaI fragment (Fig. $3 a$, lane 12; better resolution was obtained in other experiments not shown). Hybridization with pME28 (Fig. $3 a$ ) and with an IS21 probe (not shown) indicated the presence of at least two contiguous pME28 copies in the chromosome (Fig. $3 b$ ). The formation of this structure will be considered in the Discussion.

Carbenicillin enrichment for tetracycline-sensitive PAO6049 : :pME28 derivatives resulted in the isolation of strains carrying a single chromosomal IS21 insertion. This was evident from the fact that only the IS21-chromosome border fragments hybridized to pME28 (Fig. $3 a$, lanes $2,4,6,9,11$ ). Thus, the pME28 sequences had been excised, apparently by homologous recombination between the border IS21 elements (Fig. $3 b$ ).

Is pME28 insertion into the chromosome random? Whereas different insertion sites were observed in the 10 strains examined, integration was not completely random in that only two 

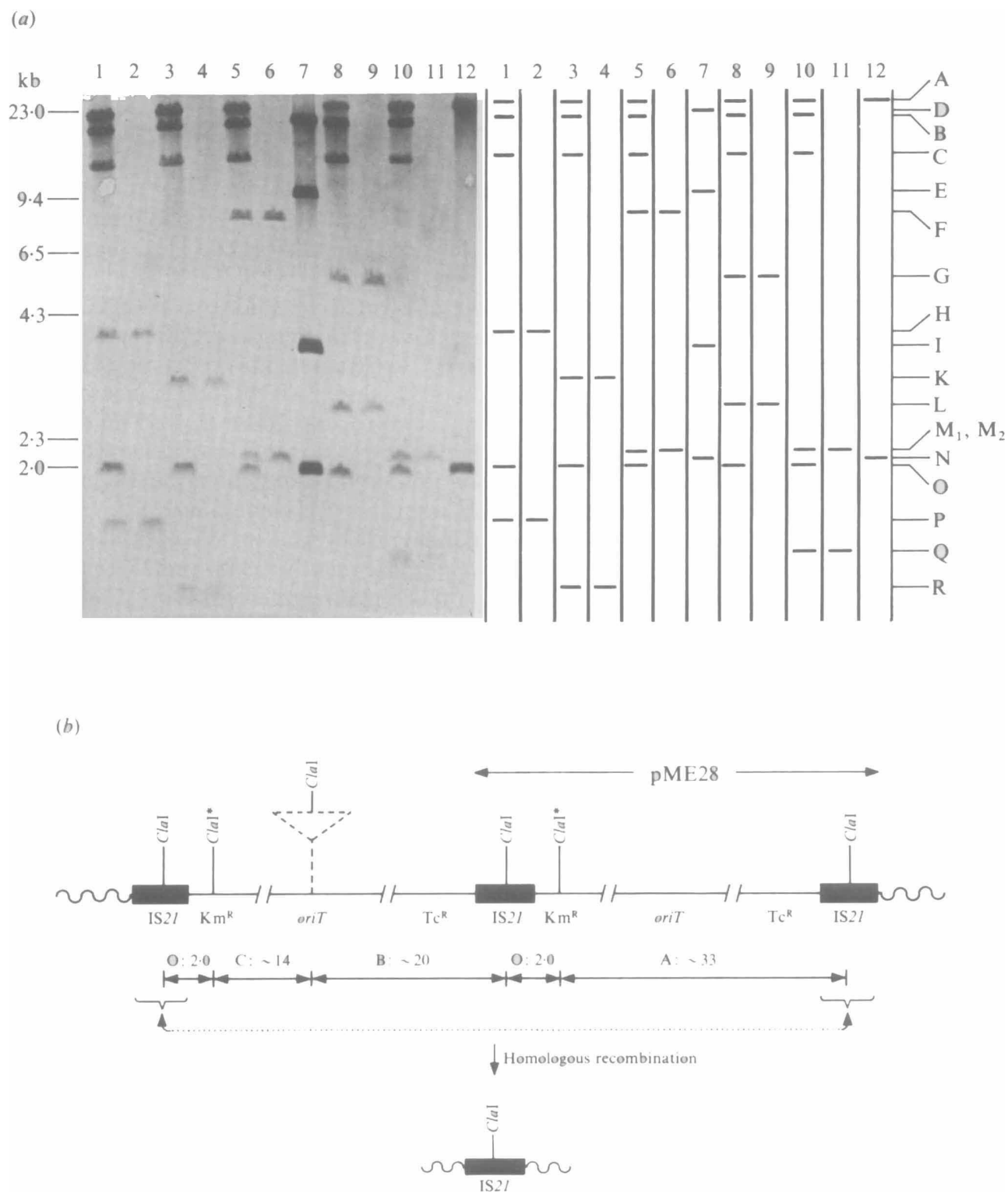

Fig. 3. Structure of chromosomally integrated pME28 and IS21. Excision of pME28 by homologous recombination $(\cdots \cdots)$ produced single IS21 insertions (see text). (a) Southern hybridization of ClaIdigested chromosomal DNA with ${ }^{35}$ S-labelled pME28. Lane 1, PAO6049::pME28-9; lane 2, PAO6049::IS21-9; lane 3, PAO6049::pME28-5; lane 4, PAO6049::IS21-5; lane 5, PAO6049::pME28-17; lane 6, PAO6049::IS21-17; lane 8, PAO6049ura::pME28; lane 9, PAO6049ura::IS21; lane 10, PAO6049trpE::pME28 = PAO6236; lane 11, PAO6049trpE::IS21; lane 12, pME28 control; all digested with ClaI. Lane 7, pME28 digested with EcoRI + PvuII. Band N is typically found in plasmids with IS 21 tandem repeats and was lost after integration; bands $F, G, H, K$, $\mathbf{L}, \mathbf{M}_{1}, \mathbf{M}_{2}, \mathbf{P}, \mathrm{Q}, \mathrm{R}$ are chromosome-IS 21 border fragments; bands $\mathrm{A}, \mathrm{B}, \mathrm{C}$ and $\mathrm{O}$ are pME28-internal fragments (band $\mathrm{O}$ is missing from the pME28 control because of methylation of $\mathrm{Cla} \mathrm{I}^{*}$ ); fragment $\mathrm{C}$ did not hybridize to an IS21 probe (not shown). (b) Proposed structure of pME28 and IS21 insertions in the $P$. aeruginosa chromosome. Letters refer to fragments in Fig. 3(a); border fragments are not shown. In one oriT a hypothetical insertion is indicated by dashed lines. Abbreviations are the same as in Fig. 1. 

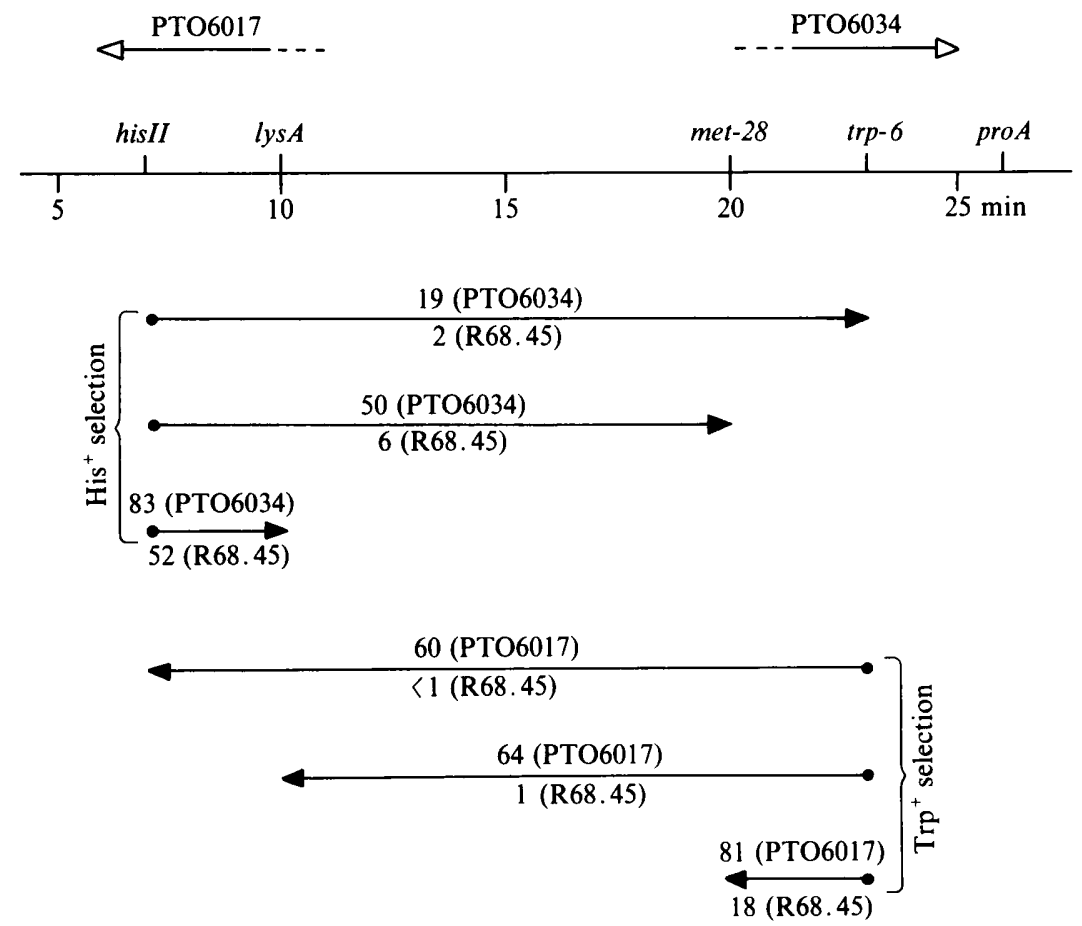

Fig. 4. Conjugational linkage in plate matings with Hfr and R68.45 donors in P. aeruginosa. The recipient was PAO236 in all crosses. The origins of the Hfr donors PTO6017 and PTO6034 are indicated by open arrows. Map locations are according to O'Hoy \& Krishnapillai (1987). Values indicate percent linkage to unselected markers (direction of filled arrows). Linkage data from R68.45 crosses are taken from Haas \& Holloway (1976).

auxotrophic mutants (one $u r a$ and one $\operatorname{trpE}$ mutant) could be recovered among 2700 pME28insertional mutants of strain PAO6049.

The chromosome of strains carrying an integrated pME28 could be mobilized by an autonomous transfer-proficient helper plasmid, pME206 (=RP1 Tcs). Hfr transfer was observed, e.g. in the trpE : :pME28 strain PAO6236 carrying pME206. Proximal markers (ser-3 at $19 \mathrm{~min}$, lys $A$ at $10 \mathrm{~min}$ ) were transferred at $10^{-2}-10^{-3}$ per donor and conjugational linkage with the multiply auxotrophic strain PAO6231 as the recipient (data not shown) confirmed that chromosome transfer originated from the trpE region at $22 \mathrm{~min}$ on the chromosome map. Transfer of the most distal chromosomal marker (trp-6 at $23 \mathrm{~min}$ ) occurred at $5 \times 10^{-6}$ per donor. All map locations are according to O'Hoy \& Krishnapillai (1987).

\section{Conjugational linkage in matings with R68.45 or Hfr donors}

In $P$. aeruginosa the piece of chromosomal DNA which is transferred during R68.45-mediated plate matings is usually short, amounting to $\leq 20 \%$ of the total chromosome length (Haas \& Holloway, 1978). When a derivative of RP1 or R68 was stably integrated into the chromosome as in the Hfr donors PTO6017 (Reimmann \& Haas, 1986) and PTO6034, longer stretches of DNA could be transferred and conjugational linkage values were higher (Fig. 4). Since the mating conditions and the recipient used were the same for all donors, the differences in linkage values must be determined by the state of the $R$ plasmid in the donors. The simplest explanation is that the association of R68.45 with the chromosome lasts for $\leq 15 \mathrm{~min}$ after initiation of conjugal DNA transfer whereas stably integrated plasmids can transfer the chromosome for much longer periods. 


\section{DISCUSSION}

Although R68.45 has been used extensively for chromosome mobilization in many different bacteria, the physical interaction of this plasmid with the chromosome had not been studied. The technical problem is that an R68.45-chromosome cointegrate is too unstable to be isolated, at least in $P$. aeruginosa. This instability is deduced from linkage data, such as those presented in Fig. 4. R68.45-mediated cotransfer of chromosomal markers located $\geq 15 \mathrm{~min}$ apart is very rare (Haas \& Holloway, 1978), whereas Hfr donors can transfer the entire length of the $P$. aeruginosa chromosome (Reimmann \& Haas, 1986).

The proposed tandem structure of chromosomally integrated pME28 (Fig. $3 b$ ) may have arisen in the following way. After insertion of one pME28 copy into the chromosome of the rec ${ }^{+}$ strain PAO6049, the conditions of antibiotic selection may have favoured amplification of the resistance determinants between the directly repeated IS21 elements, by a 'transition' mechanism (Peterson \& Rownd, 1985). To explain the ClaI fragments B (20 kb) and C (14 kb) within the integrated pME28 (Fig. $3 a$ ) we propose that a new ClaI site was created in the oriT region by the insertion of an unidentified element (Fig. $3 b$ ). The new ClaI site was found in all strains carrying chromosomal pME28 copies. We speculate that the presence of tandemly repeated ori $T$ regions (i.e. nick sites) in the chromosome of $P$. aeruginosa may be deleterious to the host and that insertional inactivation of one oriT region may stabilize the integrated plasmids. We have previously observed the same kind of insertion in one oriT region of two chromosomally integrated pME134 [= RP1 Rep(ts)] copies in $P$. aeruginosa (Reimmann \& Haas, 1986). In the case of the pME487-derived Hfr strains our model (Fig. $2 b$ ) shows a single plasmid copy integrated into the chromosome. From hybridizations with pME487 as the probe (not shown) a more complex structure appears also possible in that two or more interlocked pME487 copies may be present in the chromosome, again with insertional inactivation of $\operatorname{trf} A$ and one oriT. The main conclusion from all hybridization experiments, however, is that chromosomal copies of pME487 or pME28 do not contain any IS21 duplication.

The fact that chromosomally integrated pME487 and pME28 were bordered by single IS 21 elements is in agreement with a model which pictures R68.45-like plasmids as large, circular transposons using a 'cut-and-paste' mode of transposition (Reimmann \& Haas, 1987).

In previous work it was suggested that R68.45 could cause insertional mutations in the $P$. aeruginosa chromosome but no physical evidence was provided (Holloway et al., 1979). Our present study indicates that the R68.45-like plasmid pME28 does have mutagenic properties. Although IS21 insertions occurred in many different chromosomal sites, the target sequence cannot be totally random, as shown by the low frequency of pME28-induced auxotrophic mutations in $P$. aeruginosa.

The use of pME28 as an ori $T^{4}$ transposon similar to Tn5-Mob (Simon, 1984) is illustrated by the example of the Hfr donor PAO6236(pME206). It is also feasible to insert pME28 into another plasmid, which thus becomes mobilizable by RP1 (M. Gamper, personal communication). Occasionally, we have encountered mobilization-deficient pME28 insertions in the $P$. aeruginosa chromosome, perhaps as a consequence of secondary rearrangements within pME28 sequences but this problem did not arise in pME28-plasmid cointegrates (our unpublished results). Strains PAO6236(pME206) and PTO6034 can be added to the collection of Hfr donors now available for rapid chromosome mapping in P. aeruginosa PAO (Haas et al., 1981; O'Hoy \& Krishnapillai, 1985; Reimmann \& Haas, 1986; O’Hoy \& Krishnapillai, 1987).

We thank Franziska Brunner-Grossmann for help with some experiments, Marianne Gamper for discussion and Rosmarie Benjelloun for secretarial assistance. Carbenicillin was a gift from Beecham. This work was supported by the Schweizerische Nationalfonds (project 3.620-0.84).

\section{REFERENCES}

Bennett, P. M., Grinsted, J. \& Richmond, M. H. (1977). Transposition of TnA does not generate deletions. Molecular and General Genetics 154, 205 211 .
Borck, K., Beggs, J. D., Brammar, W. J., Hopkins, A. S. \& Murray, N. E. (1976). The construction in vitro of transducing derivatives of phage lambda. Molecular and General Genetics 146, 199-207. 
CuRriér, T. C. \& Morgan, M. K. (1982). Direct DNA repeat in plasmid $\mathbf{R} 68.45$ is associated with deletion formation and concomitant loss of chromosome mobilization ability. Journal of Bacteriology 150, 251-259.

GrinteR, N. J. (1984). Replication defective RP4 plasmids recovered after chromosomal integration. Plasmid 11, 65-73.

HAAS, D. \& HOLLOWAY, B. W. (1976). R factor variants with enhanced sex factor activity in Pseudomonas aeruginosa. Molecular and General Genetics 144, 243251.

HaAs, D. \& Holloway, B. W. (1978). Chromosome mobilization by the $R$ plasmid $R 68.45$ : a tool in Pseudomonas genetics. Molecular and General Genetics 158, 229-237.

HaAs, D. \& REImmanN, C. (1988). Use of IncP plasmids in chromosomal genetics of Gram-negative bacteria. In Promiscuous Plasmids of Gram-negative Bacteria. Edited by C. M. Thomas \& F. C. H. Franklin. London: Academic Press (in the Press).

HAAS, D. \& RIESS, G. (1983). Spontaneous deletions of the chromosome-mobilizing plasmid R68.45 in Pseudomonas aeruginosa PAO. Plasmid 9, 42-52.

haAs, D., Watson, J., Krieg, R. \& Leisinger, T. (1981). Isolation of an $\mathrm{Hfr}$ donor of Pseudomonas aeruginosa PAO by insertion of the plasmid RP1 into the tryptophan synthase gene. Molecular and General Genetics 182, 240-244.

Holloway, B. W. (1979). Plasmids that mobilize bacterial chromosome. Plasmid 2, 1-19.

Holloway, B. W. \& Morgan, A. F. (1986). Genome organization in Pseudomonas, Annual Reviews of Microbiology 40, 79-105.

Holloway, B. W., HaAs, D. \& Morgan, A. F. (1979). Interactions between $\mathbf{R}$ plasmids and the bacterial chromosome. In Microbial Drug Resistance, vol. 2, pp. 139-149. Edited by S. Mitsuhashi. Tokyo: Japan Scientific Societies Press.

IsaAC, J. H. \& Holloway, B. W. (1968). Control of pyrimidine biosynthesis in Pseudomonas aeruginosa. Journal of Bacteriology 96, 1732-1741.

Itoh, Y., Watson, J. M., HaAs, D. \& Leisinger, T. (1984). Genetic and molecular characterization of the Pseudomonas plasmid pVS1. Plasmid 11, 206220.

MARTin, R. R., Thorlton, C. L. \& UngeR, L. (1981). Formation of Escherichia coli $\mathrm{Hfr}$ strains by integrative suppression with the $\mathbf{P}$ group plasmid RP1. Journal of Bacteriology 145, 713-721.

Novick, R. P., Clowes, R. C., Cohen, S. N., CuRtiss, R., III, DATTA, N. \& FAlKow, S. (1976). Uniform nomenclature for bacterial plasmids: a proposal. Bacteriological Reviews 40, 168-189.

O'HoY, K. \& KRISHNAPILlaI, V. (1985). Transposon mutagenesis of the Pseudomonas aeruginosa PAO chromosome and the isolation of high frequency of recombination donors. FEMS Microbiology Letters 29, 299-303.
O'HoY, K. \& KRISHNAPILlaI, V. (1987). Recalibration of the Pseudomonas aeruginosa strain PAO chromosome map in time units using high-frequency-ofrecombination donors. Genetics 115, 611-618.

Peterson, B. C. \& Rownd, R. H. (1985). Drug resistance gene amplification of plasmid NR1 derivatives with various amounts of resistance determinant DNA. Journal of Bacteriology 161, 1042-1048.

ReImMANN, C. \& HAAS, D. (1986). IS21 insertion in the $\operatorname{trf} A$ replication control gene of chromosomally integrated plasmid RP1: a property of stable Pseudomonas aeruginosa $\mathrm{Hfr}$ strains. Molecular and General Genetics 203, 511-519.

ReimmanN, C. \& HaAs, D. (1987). Mode of replicon fusion mediated by the duplicated insertion sequence IS21 in Escherichia coli. Genetics 115, 619625.

Rella, M., Mercenier, A. \& HaAs, D. (1985). Transposon insertion mutagenesis of Pseudomonas aeruginosa with a Tn5 derivative: application to physical mapping of the arc gene cluster. Gene 33, 293-303.

Rella, M., Watson, J. M., Thomas, C. M. \& haAs, D. (1987). Deletions in the tetracycline resistance determinant reduce the thermosensitivity of a $\operatorname{tr} f(\mathrm{Ts})$ derivative of plasmid RP1 in Pseudomonas aeruginosa. Annales de l'Institut Pasteur/Microbiologie 138, 151-164.

Riess, G., Holloway, B. W. \& Puehler, A. (1980). R68.45, a plasmid with chromosome mobilizing ability (Cma) carries a tandem duplication. Genetical Research 36, 99-109.

Riess, G., Masepohl, B. \& Puehler, A. (1983). Analysis of IS21 mediated mobilization of plasmid pACYC184 by R68.45 in Escherichia coli. Plasmid 10, 111-118.

SimON, R. (1984). High frequency mobilization of Gram-negative bacterial replicons by the in vitro constructed Tn5-Mob transposon. Molecular and General Genetics 196, 413-420.

Simon, R., Priefer, U. \& PUehler, A. (1983). A broad host range mobilization system for in vivo genetic engineering: transposon mutagenesis in gram-negative bacteria. Bio/Technology 1, 784-790.

Stanisich, V. A. \& Holloway, B. W. (1972). A mutant sex factor of Pseudomonas aeruginosa. Genetical Research 19, 91-108.

WATSON, J. (1980). Replication mutants of IncP-1 plasmid RP1. Experientia 36, 1451.

Willetts, N. S., Crowther, C. \& Holloway, B. W. (1981). The insertion sequence IS21 of R68.45 and the molecular basis for mobilization of the bacterial chromosome. Plasmid 6, 30-52. 